\title{
Figures, Tables, Exhibits
}

\section{Figures}

Figure 4.1 Malta's tourism volumes and guest nights, 1959-2017

Figure 6.1 The continuous cyclic city-state model 76

Figure 19.1 History of the future 247

Figure 19.2 The development of mass tourism 249

Figure 19.3 The historical future of tourism: The case of Malta's policies

Figure 19.4 Jules Verne as a key to understanding Irish tourism

Figure 19.5 The growth, decline and resurgence of the city-state

Figure 19.6 Geohistorical analysis of coastal tourism in China

Figure 19.7 The future past of aircraft technology and its impact on stopover destinations

Figure 19.8 Forever young and new: Cruise tourism

Figure 19.9 From muscles to electrons: A technological look at the futures of energy, transport and tourism

Figure 19.10 Hotel history

Figure 19.11 Historical employment relations in the New Zealand tourism hotel sector: From a collective past to an individual future?

Figure 19.12 Film tourism through the ages: From Lumière to virtual reality

Figure 19.13 The evolution of the Grand Tour in the digital society 
Figure 19.14 Shopping on the edge: Identifying factors contributing to tourist retail development in heritage villages

Figure 19.15 Tourism and religion: Pilgrims, tourists and travellers - past, present and future 278

Figure 19.16 History and future of mountaineering tourism 280

Figure 19.17 Sustainability, ecotourism and Scotland: Concerns, complaints, conflicts and conservation

Figure 19.18 Mindfulness 286

$\begin{array}{lll}\text { Figure } 19.19 \text { Mobility } & 288\end{array}$

Figure 19.20 Step changes determining mass tourism 290

Figure 19.21 The leisure class of consumption 293

$\begin{array}{lll}\text { Figure 19.22 Future past } & 295\end{array}$

Figure 19.23 A conceptualization of tourism's future 296

\section{Tables}

Table 7.1 Foreign coastal concessions and ports open to foreign powers between the Nanking Treaty and the end of WWII (1842-1946)

Table 8.1 Qantas’ Kangaroo Route over time 95

$\begin{array}{lll}\text { Table 8.2 The longest hauls } & 100\end{array}$

$\begin{array}{lll}\text { Table 12.1 Key voices in the narrative } & 147\end{array}$

Table 16.1 Significant events of a religious nature 202

Table 17.1 Remarkable events in the history of modern mountaineering 222

Table 19.1 Chapter 2: Historical and future turning points 246

Table 19.2 Chapter 3: Historical and future turning points 248

Table 19.3 Chapter 4: Historical and future turning points 250

Table 19.4 Chapter 5: Historical and future turning points 253

Table 19.5 Chapter 6: Historical and future turning points 255

Table 19.6 Chapter 7: Historical and future turning points 257

Table 19.7 Chapter 8: Historical and future turning points 259 
Table 19.8 Chapter 9: Historical and future turning points 261

Table 19.9 Chapter 10: Historical and future turning points 264

Table 19.10 Chapter 11: Historical and future turning points 266

Table 19.11 Chapter 12: Historical and future turning points 268

Table 19.12 Chapter 13: Historical and future turning points 270

Table 19.13 Chapter 14: Historical and future turning points 273

Table 19.14 Chapter 15: Historical and future turning points 275

Table 19.15 Chapter 16: Historical and future turning points 277

Table 19.16 Chapter 17: Historical and future turning points 279

Table 19.17 Chapter 18: Historical and future turning points 281

\section{Exhibits}

Exhibit 19.1 Central command 283

Exhibit 19.2 Domain command 284 
